Research Article

\title{
A Comparative Study on the Thermal Conductivity of Concrete with Coal Bottom Ash under Different Drying Conditions
}

\author{
In-Hwan Yang $\mathbb{D}^{1},{ }^{1}$ Jihun Park, ${ }^{1}$ Kyoung-Chul Kim, ${ }^{2}$ and Sung-Won Yoo ${ }^{3}$ \\ ${ }^{1}$ Kunsan National University, Department of Civil Engineering, Daehak-Ro 558, Kunsan, Jeonbuk 54150, Republic of Korea \\ ${ }^{2}$ Korea Institute of Civil Engineering and Building Technology, Structural Engineering Research Institute, Goyang, \\ Gyeonggi 10223, Republic of Korea \\ ${ }^{3}$ Gachon University, Department of Civil and Environmental Engineering, Seongnamdaero 1342, Seongnam, \\ Gyeonggi 13120, Republic of Korea \\ Correspondence should be addressed to In-Hwan Yang; ihyang@kunsan.ac.kr
}

Received 20 July 2021; Accepted 15 November 2021; Published 2 December 2021

Academic Editor: Kim Hung Mo

Copyright ( 2021 In-Hwan Yang et al. This is an open access article distributed under the Creative Commons Attribution License, which permits unrestricted use, distribution, and reproduction in any medium, provided the original work is properly cited.

\begin{abstract}
The utilization of coal bottom ash (CBA) and fly ash in concrete has become more common. For CBA concrete, curing conditions would influence the thermal properties of the concrete due to the high water absorption capacity of the CBA aggregate. In addition, CBA and fly ash contents in concrete affect the thermal properties of the concrete. Therefore, the effects of the drying conditions and the CBA and fly ash contents on the thermal conductivity of CBA concrete were investigated in this study. The thermal conductivity of concrete was measured under two different curing and drying conditions: oven-dried conditions and saturated surface-dry (SSD) conditions, with curing times of 28 and 91 days. The concrete mixtures also contained different levels of CBA and fly ash. Crushed sand in the concrete mixtures was replaced by CBA with replacement ratios of $25 \%, 50 \%, 75 \%$, and $100 \%$ by volume. In addition, cement in the concrete mixture was substituted by fly ash with replacement ratios of 20 and $40 \%$ by volume. The thermal conductivity of concrete under the oven-dried conditions was much lower than that under the SSD conditions. Moreover, the thermal conductivity of the concrete decreased as the CBA content increased under both the oven-dried and SSD conditions. The material properties of the concrete, including unit weight, compressive strength, and ultrasonic velocity, were also measured in the study. Compared with the SSD conditions, the compressive strength, unit weight, and ultrasonic velocity of CBA concrete were considerably lower under the oven-dried conditions. Moreover, the relationships between the thermal conductivity and unit weight, compressive strength, and ultrasonic velocity were suggested.
\end{abstract}

\section{Introduction}

Recently, global climate change has led to an increase in energy consumption for cooling in hot weather and for heating in cold weather. Applying lightweight concrete to construction materials for buildings is favorable because it reduces the use of energy in buildings and promotes efficient energy consumption [1-5]. The thermal properties of construction materials used for concrete buildings are strongly dependent on the porous aggregates and density of the material because a material with porous aggregates exhibits a low thermal conductivity [3].
Coal bottom ash (CBA) is considered to be favorable for the fabrication of concrete with low thermal conductivity because of its porous structure [6]. The thermal conductivity of mortar using CBA aggregates decreased by $64 \%$ when CBA was applied to the mortar mixture [7]. Ngohpok et al. [8] investigated the material properties of pervious concrete containing recycled and bottom ash aggregates. This study suggested that the use of CBA in pervious concrete significantly reduced the thermal conductivity of the concrete. Park et al. [9] also investigated the selected strength properties of CBA concrete under different curing and drying conditions. In addition, Gooi et al. [10] concluded that the 
application of CBA concrete is a promising method for improving the energy efficiency of buildings.

Moreover, fly ash also influences the thermal conductivity of concrete. The heat flow resistance of fly ash is $15 \sim 40 \%$ greater than that of quartz sand [11]. However, the heat flow resistance of fly ash is affected by the moisture content, so it could decrease dramatically under higher moisture conditions. The effect of fly ash content on the thermal and mechanical properties of lightweight concrete was analyzed in the study by Zhou and Brooks [12]. Their test results revealed that lightweight concrete containing fly ash exhibited a low thermal conductivity but maintained its mechanical strength. Brooks et al. [4] compared the thermal and mechanical properties of concrete containing four different types of lightweight fillers, which included fly ash. According to their study, the thermal conductivity of concrete decreased as the fly ash content increased, and the density of the concrete containing fly ash was higher than that of the other concrete used in the study.

However, although CBA and fly ash affect the thermal conductivity of concrete, most studies exclusively evaluate the influence of only CBA or fly ash on the thermal conductivity of the resulting concrete. Studies on the effect of CBA and fly ash contents on the thermal conductivity of concrete in which they are used simultaneously are still limited. Ghosh et al. [13] investigated the thermal properties of mortar containing fly ash and CBA as a sand replacement. Additionally, there are very few studies investigating the effect of moisture contents or drying conditions on the thermal conductivity of lightweight concrete containing both CBA and fly ash. Khan [14] investigated the thermal conductivity of conventional concrete at various moisture contents and showed that the thermal conductivity of concrete was influenced by the moisture content. According to the study of Zhang et al. [15], the thermal conductivity of conventional concrete containing limestone and granite as coarse aggregates increased as the saturation degree in the concrete increased.

Moreover, the utilization of CBA and fly ash is expected to reduce the thermal conductivity of concrete. The thermal conductivity of concrete containing CBA and fly ash could be also affected by the drying conditions or moisture content inside the concrete because of the high water absorption capacity of CBA [3-5].

CBA concrete may be favorable to reduce the thermal conductivity in the walls of buildings but unfavorable to increase the strength of concrete structures due to lightweight of the concrete. The moisture content of concrete depends on curing and drying conditions. Eventually, curing and drying conditions influence the strength properties and thermal properties of the concrete. Therefore, the effect of curing and drying conditions on both the strength properties and thermal properties of CBA concrete is important. The study on the effect of curing and drying conditions on strength properties including the compressive strength, splitting tensile strength, and flexural tensile strength was performed in the earlier study [9]. However, the study on the effect of curing and drying conditions on the thermal conductivity of concrete containing CBA and fly ash is very limited and accordingly the study on the effect of curing and drying conditions on thermal conductivity of concrete should be analyzed.

Therefore, this study aimed to highlight the effect of curing and drying conditions on the thermal conductivity of concrete containing CBA as the replacement of fine aggregate and fly ash as the replacement of cement, respectively. In particular, the thermal conductivity of concrete under saturated surface-dry (SSD) conditions and ovendried conditions was investigated. Additionally, the material properties of the concrete used were analyzed at various CBA and fly ash contents.

\section{Materials}

The crushed natural coarse aggregate used in the mixture had a maximum size of $20 \mathrm{~mm}$ and a density of $2.60 \mathrm{~g} / \mathrm{cm}^{3}$. The sand used as fine aggregate had a maximum size of $5 \mathrm{~mm}$ and a density of $2.61 \mathrm{~g} / \mathrm{cm}^{3}$. The material properties of the coarse and fine aggregates, including density and water absorption, were measured as shown in Table 1. Figure 1 also provides the particle size distributions of the natural fine and coarse aggregates.

CBA was obtained from a thermal power plant and used as a fine aggregate substitution. CBA used in this study was collected from a commercial thermal power plant (Korea South-East Power Co., Ltd., Yeongheung Power Division, Yeongheung, Korea). The thermal power plant operates a rigorous waste treatment program, and thus, CBA was collected from this power plant. In addition, to secure the consistency of the CBA, it was chosen from the same batch of the production process. CBA is a by-product resulting from burning coal fuel at thermal power plants. Coal fuel supplied from different sources or burnt under different production process causes some variation in the properties of CBA. Therefore, to avoid such variations and secure the consistency of the CBA as much as possible, the supplier confirmed that the CBA used in this study had been supplied from the same source and produced in the same batch. Moreover, to examine the components of the CBA, some CBA samples were randomly selected and analyzed by using $\mathrm{X}$-ray fluorescence spectrometry (XRF). The results of the analysis of the components for the CBA, as shown in Table 2, showed that the compositions of the samples were similar, which ensured the consistency of the CBA.

The properties of concrete containing CBA are dependent on those of the CBA. To secure the reproducibility of the results of tests performed to investigate the characteristics of CBA concrete, it is important to obtain CBA that is produced in the same batch and obtained from same source because test results can differ due to the different production processes used to make CBA.

Before CBA was mixed in the concrete mixture, it was ground until reaching a size distribution similar to that of the fine aggregate. To substitute the crushed fine aggregates in the mixture, CBA particles with sizes in the range between 0.15 and $5.0 \mathrm{~mm}$ were retained. Figure 2 provides the size distribution when the natural fine aggregate was replaced by $\mathrm{CBA}$ at various replacement ratios. It was assumed that the 
TABLE 1: Physical properties of the used aggregates.

\begin{tabular}{lcc}
\hline Aggregate & Water absorption $(\%)$ & Density $\left(\mathrm{g} / \mathrm{cm}^{3}\right)$ \\
\hline CBA & 3.88 & 1.84 \\
Coarse aggregate & 1.02 & 2.60 \\
Fine aggregate & 0.64 & 2.61 \\
\hline
\end{tabular}

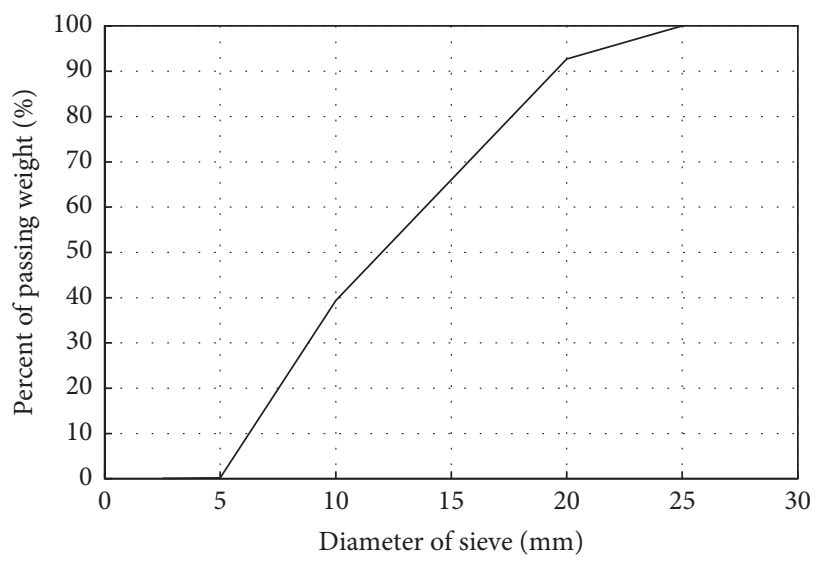

(a)

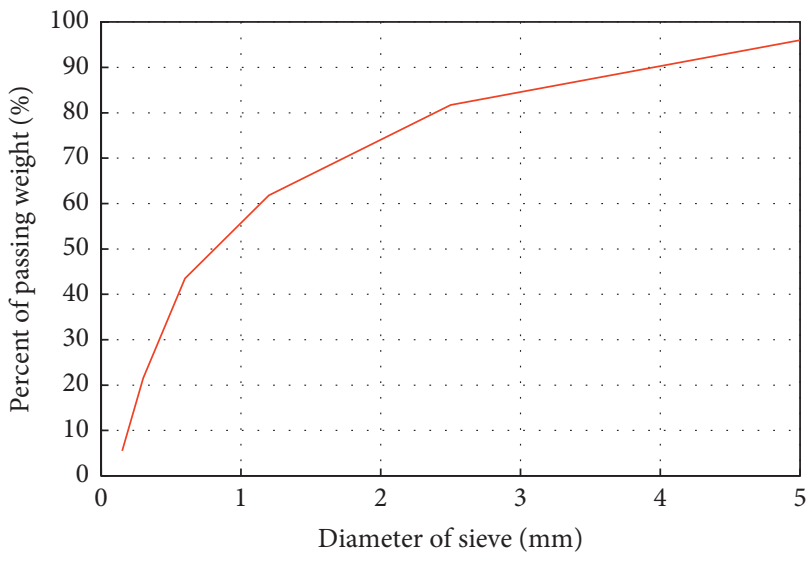

(b)

Figure 1: Sieve analysis of the coarse and fine aggregates. (a) Coarse aggregate. (b) Fine aggregate.

TABle 2: Chemical composition of coal bottom ash, fly ash, and OPC.

\begin{tabular}{lccc}
\hline Component & CBA (\%) & Fly ash (\%) & OPC (\%) \\
\hline $\mathrm{Al}_{2} \mathrm{O}_{3}$ & 26.20 & 22.10 & 4.59 \\
$\mathrm{CaO}$ & 3.93 & 6.42 & 65.00 \\
$\mathrm{SiO}_{2}$ & 55.70 & 55.80 & 17.60 \\
$\mathrm{Fe}_{2} \mathrm{O}_{3}$ & 7.53 & 9.26 & 3.43 \\
$\mathrm{~K}_{2} \mathrm{O}$ & 1.17 & 1.30 & 1.13 \\
$\mathrm{Na}_{2} \mathrm{O}$ & 0.76 & 1.33 & 0.19 \\
$\mathrm{MgO}$ & 1.09 & 1.69 & 3.53 \\
$\mathrm{SO}_{3}$ & 0.76 & - & 3.76 \\
\hline
\end{tabular}

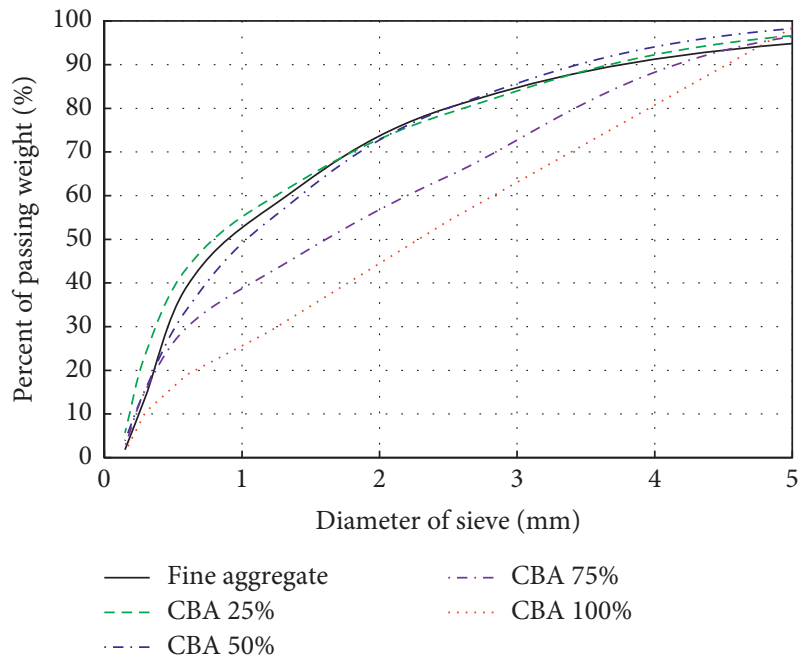

Figure 2: Sieve analysis of the combinations of CBA and fine aggregate at different replacement ratios. variation in the size distribution when incorporating both fine aggregate and CBA would affect the density of the CBA concrete, which is related to the thermal conductivity of concrete. Table 1 shows the physical properties of CBA and natural coarse and fine aggregate. Compared to the fine aggregate, CBA had a lower density with a value of $1.84 \mathrm{~g} /$ $\mathrm{cm}^{3}$, but its water absorption was 6 times greater than that of fine aggregate. The specific surface area of the CBA used in this study was not measured. Thus, CBA particles were dried under SSD conditions before being added to the mixture. Table 2 lists the chemical compositions of CBA and fine aggregate. The table shows that CBA contained a high silicon dioxide $\left(\mathrm{SiO}_{2}\right)$ content, exceeding $50 \%$ of the total components.

Ordinary Portland cement (OPC) has a specific gravity of $3.15 \mathrm{~g} / \mathrm{cm}^{3}$ and a specific surface area of $2,800 \mathrm{~cm}^{2} / \mathrm{g}$. OPC was combined with fly ash as the binder in the mixtures. The specific gravity and specific surface area of fly ash were $2.61 \mathrm{~g} / \mathrm{cm}^{3}$ and $3,650 \mathrm{~cm}^{2} / \mathrm{g}$, respectively. Table 2 shows that both CBA and fly ash contain large amounts of $\mathrm{Al}_{2} \mathrm{O}_{3}$ and $\mathrm{SiO}_{2}$, improving the pozzolanic reaction in the concrete.

\section{Experimental Program}

3.1. Mixing Proportions. Two series of mixtures in terms of fly ash contents were fabricated, as shown in Table 3 in this study, which were applied in the earlier study [9]. For the first mixture series, OPC was substituted with fly ash at a volume ratio of $20 \%$. Additionally, fine aggregate was substituted with CBA at volume ratios of $25 \%, 50 \%, 75 \%$, and $100 \%$. In addition, the influence of curing time was also considered. For the second mixture series, OPC was substituted with fly ash at a volume ratio of $40 \%$. CBA was 
TABLE 3: Mixing proportions.

\begin{tabular}{|c|c|c|c|c|c|c|c|c|}
\hline \multirow{3}{*}{ Mixture } & \multirow{3}{*}{$\mathrm{w} / \mathrm{b}$} & \multirow{3}{*}{ CBA content by volume (\%) } & \multicolumn{6}{|c|}{ Unit weight $\left(\mathrm{kg} / \mathrm{m}^{3}\right)$} \\
\hline & & & \multirow{2}{*}{ Water } & \multicolumn{2}{|c|}{ Binder } & \multicolumn{2}{|c|}{ Fine aggregate } & \multirow{2}{*}{ Coarse aggregate } \\
\hline & & & & $\mathrm{OPC}$ & FA & Natural & CBA & \\
\hline F4-B000 & 0.34 & 0 & 178.5 & 357.0 & 168.5 & 650.0 & 0.0 & 878.5 \\
\hline F4-B050 & 0.34 & 50 & 178.5 & 357.0 & 168.5 & 325.0 & 230.7 & 878.5 \\
\hline F4-B100 & 0.34 & 100 & 178.5 & 357.0 & 168.5 & 0.0 & 461.4 & 878.5 \\
\hline $\mathrm{F} 2-\mathrm{B} 000$ & 0.32 & 0 & 178.5 & 476.0 & 84.2 & 650.0 & 0.0 & 878.5 \\
\hline F2-B025 & 0.32 & 25 & 178.5 & 476.0 & 84.2 & 487.5 & 115.4 & 878.5 \\
\hline F2-B050 & 0.32 & 50 & 178.5 & 476.0 & 84.2 & 325.0 & 230.7 & 878.5 \\
\hline F2-B075 & 0.32 & 75 & 178.5 & 476.0 & 84.2 & 162.5 & 346.1 & 878.5 \\
\hline $\mathrm{F} 2-\mathrm{B} 100$ & 0.32 & 100 & 178.5 & 476.0 & 84.2 & 0.0 & 461.4 & 878.5 \\
\hline
\end{tabular}

Notes: OPC: ordinary Portland cement; FA: fly ash; CBA: coal bottom ash; w/b: water-to-binder ratio.

also used to replace fine aggregate at two different ratios of $50 \%$ and $100 \%$ by volume in this mixing series. According to the ACI 211 committee [16], replacing cement with fly ash should be in the range of $10 \%$ to $35 \%$ to obtain the benefits from fly ash usage. The recommended maximum value from the ACI 211 corresponds approximately to the replacement ratio of $40 \%$. Therefore, OPC was replaced with fly ash at a volume ratio of $40 \%$. Additionally, compared to concrete with fly ash at a replacement ratio of $20 \%$, concrete with fly ash with a replacement ratio of $40 \%$ could be differentiated more clearly due to its higher replacement ratio.

Water-to-binder ratios of 0.32 and 0.34 were applied in the first and second mixing series, respectively. In particular, due to the high water absorption of CBA, CBA and natural aggregates were dried under SSD conditions before being mixed. To improve the workability of the fresh concrete, an air-entraining admixture of 6.72 and $6.31 \mathrm{~kg} / \mathrm{m}^{3}$ and the HWRAs of 1.88 and $1.77 \mathrm{~kg} / \mathrm{m}^{3}$ were added to $\mathrm{F} 2$ and $\mathrm{F} 4$ series mixtures, respectively.

3.2. Curing and Drying of Concrete. According to the KS F 2405 standard [17], to evaluate the unit weight and compressive strength of CBA concrete, cylindrical concrete specimens with dimensions of $100 \mathrm{~mm} \times 200 \mathrm{~mm}$ were cast. Two different curing and drying conditions were incorporated in this study.

For the water curing and SSD conditions, the cylindrical concrete specimens were demolded after 24 hours of pouring concrete into molds and then cured in a water storage at $23 \pm 2{ }^{\circ} \mathrm{C}$ until one day before testing [18]. Thereafter, the moisture on the surface of cylindrical concrete specimen was removed by towels, and finally, they were kept at room temperature in the laboratory before the measurement. In contrast, for the air curing and oven-dried conditions, the cylindrical concrete specimens were demolded after 24 hours of pouring concrete into molds and then cured in a water storage at $23 \pm 2^{\circ} \mathrm{C}$ for 7 days. After that, they were cured at room temperature in the laboratory until one day before testing. Finally, the cylindrical concrete specimens were oven-dried in a chamber at $105 \pm 5^{\circ} \mathrm{C}$ for 24 hours before the testing.

In brief, hereafter, the water curing and SSD conditions are designated the SSD conditions, and the air curing and ovendried conditions are designated the oven-dried conditions.
3.3. Measurement of Thermal Properties. To measure the thermal conductivity of solid materials, there are several methods such as ASTM D 5334-05 [19], the two linear parallel (TLPP) method [20], and the transient plane source (TPS) method [21, 22]. Among these techniques, the TPS method has been widely used to measure the thermal conductivity of concrete. The measurement technique for the thermal conductivity used in this study was based on the TPS method. The thermal conductivity of CBA concrete specimens was measured using a TPS1500 testing device supplied by Hot Disk Ltd. (Gothenburg, Sweden), as shown in Figure 3. The hot disk sensor was inserted between two half-cylinders for measuring the thermal conductivity. The cut surfaces of the concrete specimen were polished to ensure an even surface before inserting the sensor. Electric voltage was introduced into the thermal sensor, and the sensor elements were heated when the TPS1500 device was operated. At this point, the sensor probed the thermal conductivity of the concrete specimens. This procedure was implemented three times for at least 90 minutes to ensure measurement accuracy, considering the thermal equilibrium of the concrete specimens. The measurement of the thermal conductivity of the CBA concrete was performed under the SSD and oven-dried conditions with curing ages of 28 and 91 days.

3.4. Measurement of Material Properties. The unit weight (bulk density) of the CBA concrete was evaluated under SSD and oven-dried conditions with curing ages of 28 and 91 days. A curing age of 28 days is typically used for the design of structural concrete. Additionally, the application of CBA and fly ash is expected to improve the strength properties of concrete prepared with long-term curing because of the pozzolanic properties of these two additives. Therefore, this study was focused on investigating the material properties of CBA concrete after curing for 28 and 91 days.

The dimensions and weights of three different cylindrical concrete specimens were measured. Then, the unit weight of CBA concrete was carefully measured three times and finally, the mean value of the unit weights of the CBA concrete was calculated. This measurement procedure implied that the possibility of human errors in the measurements was very low. Therefore, it was assumed that the test results were attributed to only the test variables. 
Additionally, three cylindrical specimens of each series were tested by using a universal testing machine with a capacity of $2000 \mathrm{kN}$ to evaluate the compressive strength of the CBA concrete in accordance with KS F 2405 [17]. The mean compressive strengths of the CBA concrete under SSD and oven-dried conditions were determined.

Finally, three cylindrical specimens were used to examine the ultrasonic velocity of the CBA concrete in accordance with ASTM C597-09 [23]. The instrument for measuring ultrasonic velocity included two transducers: a pulse generator and a receiver. It is recommended that an ultrasonic pulse with a frequency of $50 \sim 55 \mathrm{kHz}$ is suitable for measuring the ultrasonic velocity of concrete [23-25]. Therefore, an instrument with a pulse frequency of $54 \mathrm{kHz}$ was used in this study. The mean ultrasonic velocities of the CBA concrete under the SSD and oven-dried conditions were presented.

\section{Test Results and Discussions}

4.1. Thermal Conductivity of CBA Concrete. Figure 4(a) presents the thermal conductivity of CBA concrete with different fly ash contents (F2 and F4 series) and under different drying conditions at a curing age of 28 days. The $\mathrm{S}$ and $\mathrm{D}$ characteristics in the legend of the figure represent the SSD and oven-dried conditions, respectively.

The thermal conductivity of CBA concrete decreased when the drying condition was changed from SSD conditions to oven-dried conditions. Specifically, for the F2 series concrete specimens with CBA contents of $0 \%, 25 \%, 50 \%$, $75 \%$, and $100 \%$, the thermal conductivities of the concrete under the oven-dried conditions decreased by $15.9 \%, 18.1 \%$, $18.4 \%, 18.0 \%$, and $19.0 \%$, respectively, compared to the concrete under SSD conditions. Regarding the F4 series of concrete with CBA contents of $0 \%, 50 \%$, and $100 \%$, the thermal conductivities of the concrete under oven-dried conditions decreased by $17.2 \%, 20.6 \%$, and $15.6 \%$, respectively, compared to the concrete under SSD conditions. Finally, the test results implied that the thermal conductivity of the CBA concrete prepared under oven-dried conditions decreased significantly. Concrete with high thermal conductivity increases heat loss through walls in building structures. Therefore, the application of concrete with low thermal conductivity, such as the CBA concrete analyzed in this study, can reduce heat transfer, thus energy consumption in building structures.

The decrease in the thermal conductivity of CBA concrete prepared under oven-dried conditions was attributed to its low moisture content and hydration degree due to the different curing procedures of the concrete specimens. Concrete specimens cured under SSD conditions retained moisture because the specimens were kept for only one day at room temperature after they were taken out of the water tank, and then the moisture on the concrete surface was removed. Therefore, compared to concrete cured under oven-dried conditions, the thermal conductivity of concrete cured under SSD conditions is expected to be higher due to higher moisture content inside the porous concrete. SSD conditions are ideal because the concrete specimen is fully saturated with moisture at the measurement time. Ovendried conditions are also ideal because concrete specimens are assumed to be dried completely at the measurement time. The SSD conditions and oven-dried conditions investigated in this study are two extreme conditions. The moisture content of actual concrete specimens depends on the environmental conditions and humidity to which they are subjected.

Water evaporation due to oven-drying methods increased the number of pores without moisture in the CBA concrete; thus, the thermal conductivity of the CBA concrete decreased under oven-dried conditions. Moreover, this tendency was similar to the results from some previous studies on conventional concrete [20,26,27]. Kim et al. [20] showed that the moisture content in concrete specimens was the main factor affecting the thermal conductivity of conventional concrete. Nguyen et al. [28] investigated the influence of moisture content on the thermal conductivity of concrete, including various types of lightweight aggregates. They found that the thermal conductivity of lightweight concrete increased almost linearly with the moisture content. Additionally, the specific surface area of the CBA can affect the thermal conductivity and strength properties of concrete because the specific surface area of the CBA affects the acceleration of the pozzolanic reaction [29].

The effect of CBA content on the thermal conductivity of CBA concrete is also shown in Figure 4(a). The thermal conductivity of the F2 series under SSD conditions decreased gradually as the CBA content increased. The thermal conductivity of the F2 series specimens under SSD conditions decreased gradually by $3.9 \%, 9.1 \%, 11.7 \%$, and $15.0 \%$ as the natural fine aggregate was replaced with $25 \%, 50 \%, 75 \%$, and $100 \% \mathrm{CBA}$, respectively. A decreasing tendency in the thermal conductivity of the F4 series under SSD conditions with the CBA content was also observed. The thermal conductivity of the $\mathrm{F} 4$ series decreased from $1.77 \mathrm{~W} / \mathrm{m} \bullet \mathrm{K}$ to $1.46 \mathrm{~W} / \mathrm{m} \bullet \mathrm{K}$ when the substitution of fine aggregate with CBA increased from $0 \%$ to $100 \%$. In addition, the thermal conductivities of the F2 and F4 series under oven-dried conditions decreased gradually. The thermal conductivity of the F2 series decreased from $1.54 \mathrm{~W} / \mathrm{m} \bullet \mathrm{K}$ to $1.27 \mathrm{~W} / \mathrm{m} \bullet \mathrm{K}$, while that of the $\mathrm{F} 4$ series decreased from $1.47 \mathrm{~W} / \mathrm{m} \bullet \mathrm{K}$ to $1.23 \mathrm{~W} / \mathrm{m} \bullet \mathrm{K}$. Due to the pore structure of CBA, the concrete mixture containing CBA caused the porosity of the concrete to increase. Therefore, the thermal conductivity of CBA concrete decreased.

The influence of the fly ash content on the thermal conductivity of CBA concrete is shown in Figure 4(a). Strictly speaking, the thermal conductivity of the F4 series was lower than that of the F2 series, but the difference was not significant. Brooks et al. [4] investigated the effect of fly ash on the thermal properties of concrete under SSD conditions. Their test results provided that the thermal conductivity of the concrete significantly decreased as fly ash content in the mixture increased. Therefore, the comparison of the thermal conductivity results from this study and the previous study implied that the characteristics of fly ash, which depended on its source, could affect the thermal conductivity of CBA concrete containing fly ash. 


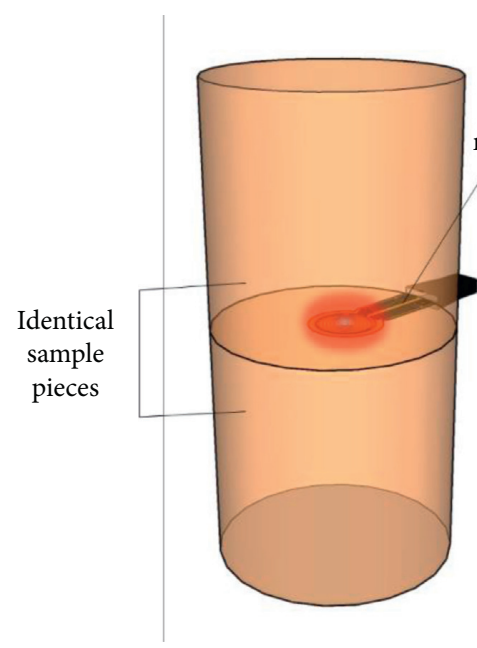

(a)

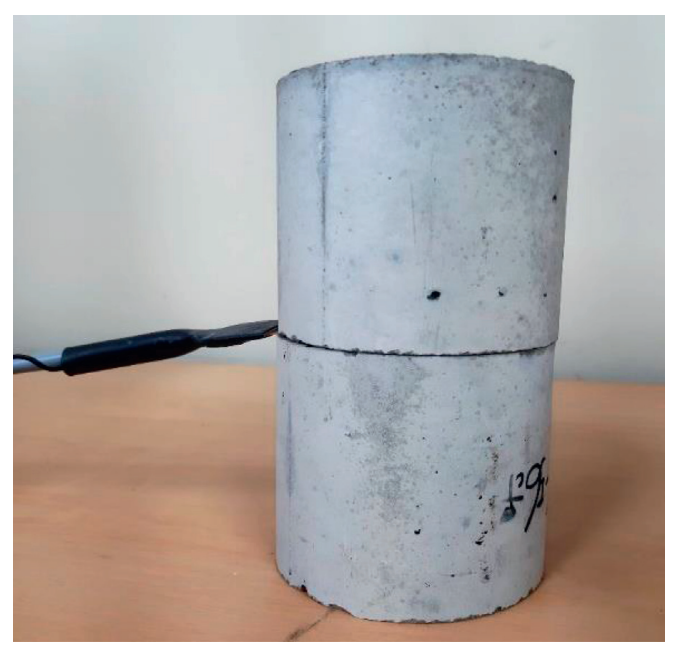

(b)

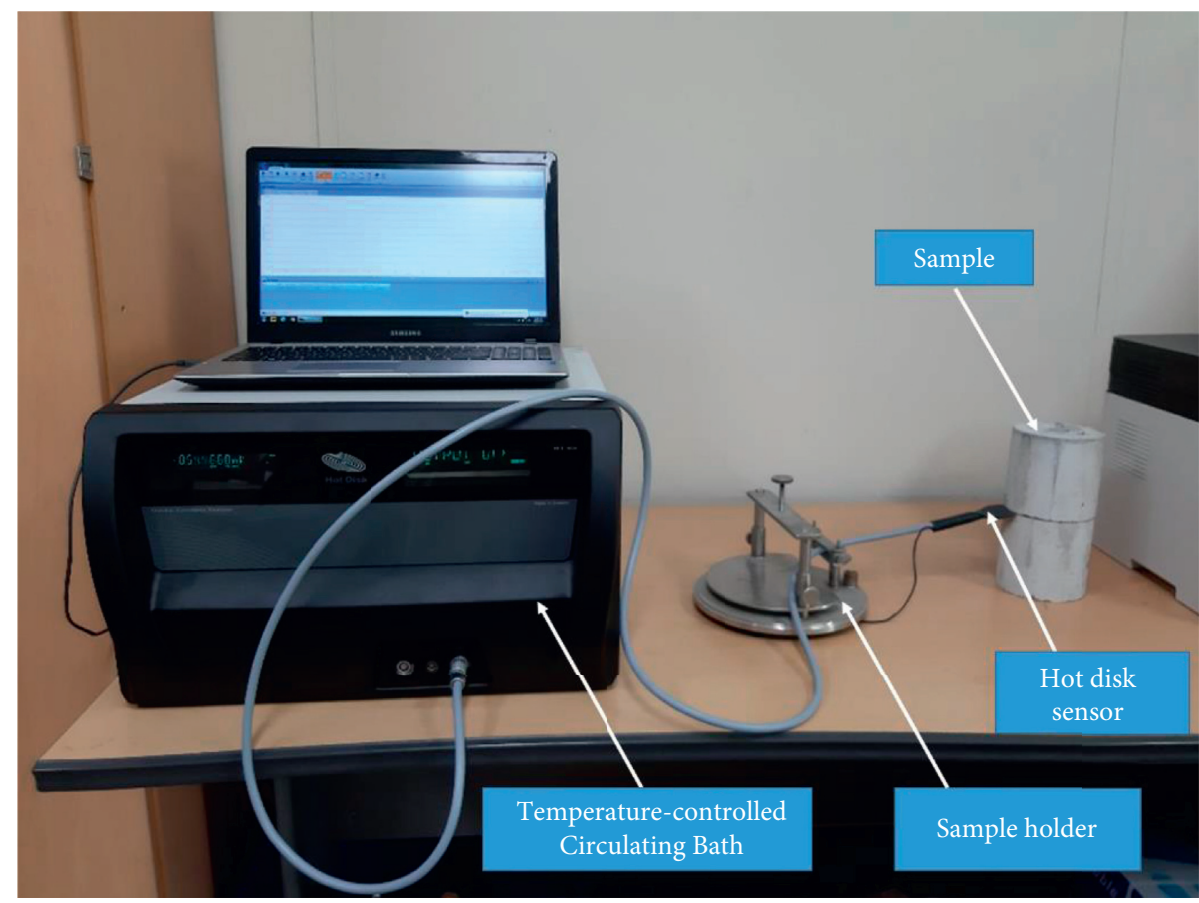

(c)

FIgURE 3: Instrument for measuring thermal conductivity. (a) Illustration of the TPS test. (b) Tested cylinder. (c) Test setup.

Figure 4(b) presents the effect of curing age on the thermal conductivity of the F2 series. The figure shows that the thermal conductivity of CBA concrete increased with curing age. Specifically, regarding CBA concrete under SSD conditions, the thermal conductivities of the F2-BA00, F2-BA025, F2-BA050, and F2-BA100 specimens increased by 5.8\%, 5.4\%, 7.8\%, 5.1\%, and $5.8 \%$, respectively, when the curing age was extended from 28 to 91 days. Regarding CBA concrete under oven-dried conditions, the thermal conductivity of the concrete at 91 days was $8.0 \sim 14.4 \%$ greater than that of the concrete at 28 days.

4.2. Unit Weight of CBA Concrete. The unit weight of CBA concrete under different curing and drying conditions with a curing age of 28 days is shown in Figure 5(a). The unit weight of CBA concrete decreased as the drying condition shifted from SSD conditions to oven-dried conditions. Regarding the F2 series specimens with various CBA contents, the unit weight under SSD conditions was 3.3 4.1\% greater than that under oven-dried conditions. Regarding the F4 series with various CBA contents, the unit weight under SSD conditions was also $3.4 \sim 4.8 \%$ greater than that under oven-dried conditions. Therefore, the test results implied that the drying condition of the specimens had an effect on the unit weight of CBA concrete. This phenomenon might be caused by the water evaporation of specimens containing CBA due to oven-drying.

The influence of CBA content on the unit weight of CBA concrete is also found in Figure 5(a). The unit weights of CBA concrete decreased as the CBA content increased. The 


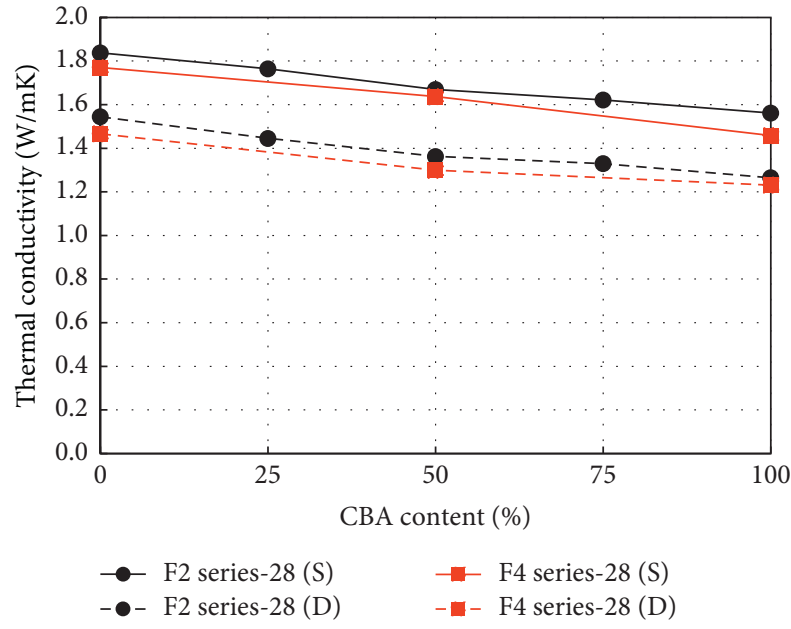

(a)

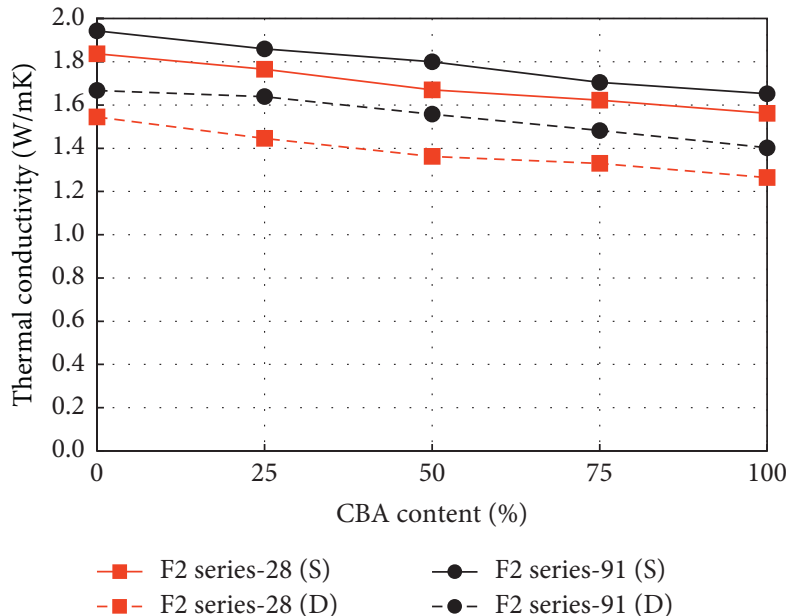

(b)

Figure 4: Thermal conductivity of CBA concrete. (a) Comparison under different drying conditions. (b) Comparison at different curing ages.

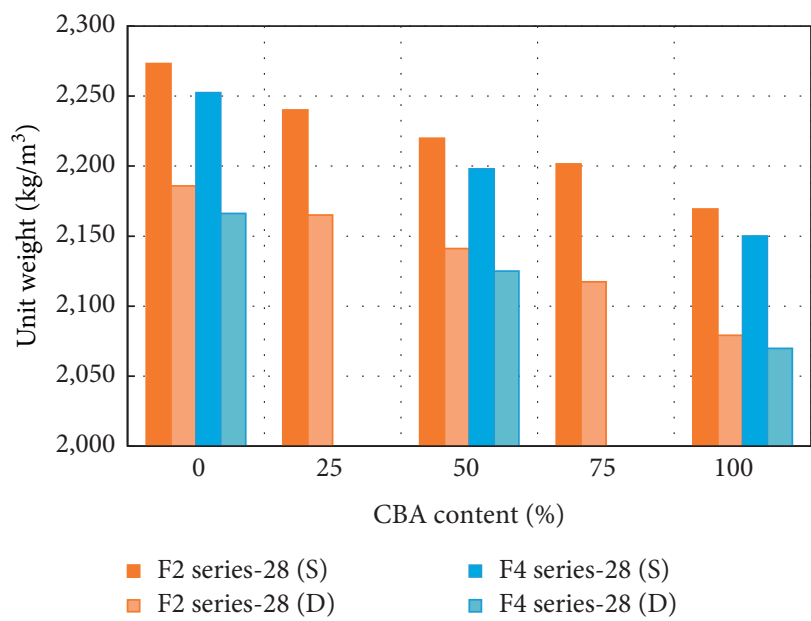

(a)

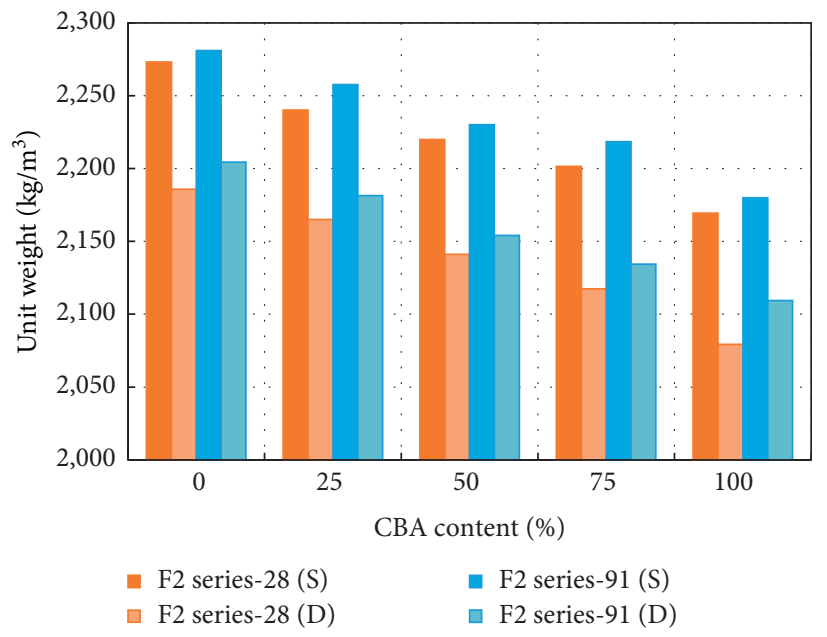

(b)

Figure 5: Unit weight of CBA concrete. (a) Comparison under different drying conditions. (b) Comparison at different curing ages.

unit weight of the F2 series concrete specimens under SSD conditions decreased from $2,273 \mathrm{~kg} / \mathrm{m}^{3}$ to $2,169 \mathrm{~kg} / \mathrm{m}^{3}$ as the CBA content increased from $0 \%$ to $100 \%$. The unit weight of the F2 series concrete specimens under oven-dried conditions decreased from $2,185 \mathrm{~kg} / \mathrm{m}^{3}$ to $2,079 \mathrm{~kg} / \mathrm{m}^{3}$ as the CBA content increased from $0 \%$ to $100 \%$, as similarly analyzed in the study of Park et al. [9]. A decrease in the unit weight was also observed in the F4 series specimens. The unit weight of the F4 series decreased by $4.4 \%$ under SSD conditions and by $4.5 \%$ under oven-dried conditions when the CBA content increased up to $100 \%$. The decrease in the unit weight with the CBA content was due to the high porosity of CBA. A large decrease in unit weight due to CBA content under SSD conditions was reported in the study by Singh and Siddique [30]. In their study, the decrease in the unit weight reached approximately $10 \%$ as the CBA content increased from 20 to $100 \%$, which was due to the low density of the CBA aggregate. However, the addition of the fly ash to the concrete mixture might make the microstructure of the concrete denser; the decrease in unit weight in this study was lower than that in the previous study.

Moreover, the unit weights of the F2 and F4 series were compared to investigate the effect of fly ash content on unit weight. Overall, the unit weight of the F4 series was lower than that of the F2 series under both SSD and oven-dried conditions; however, this result was not significant. Specifically, under SSD conditions, the unit weights of the F4 series specimens containing $50 \%$ and $100 \%$ CBA were approximately $0.9 \%$ lower than those of the F2 series specimens containing $50 \%$ and $100 \%$ CBA. Under oven-dried conditions, the unit weights of the F4 series specimens containing $50 \%$ and $100 \%$ CBA were approximately $0.5 \sim 0.8 \%$ lower than those of the F2 series specimens containing $50 \%$ and $100 \%$ CBA. 
The comparison of the unit weight of the F2 series specimens at the two different curing ages is presented in Figure 5(b). The unit weight of the F2 series specimens under the SSD and oven-dried conditions was improved as the curing age was increased; however, the improvement was not great.

4.3. Compressive Strength of CBA Concrete. The compressive strength of CBA concrete under oven-dried conditions was significantly lower than that of CBA concrete under SSD conditions, as shown in Figure 6(a). The compressive strength of the F2 and F4 series specimens decreased considerably under oven-dried conditions. The comparison of the compressive strengths of concrete with different CBA contents is also shown in Figure 6(a). The compressive strength of concrete decreased as the CBA content increased under both the oven-dried and SSD conditions. The compressive strength of the F2 series under SSD conditions decreased gradually by $4.1 \%, 5.9 \%, 7.0 \%$, and $10.7 \%$ as the fine aggregate was replaced with $25 \%, 50 \%, 75 \%$, and $100 \%$ CBA, respectively. In addition, the compressive strength of the F2 series under oven-dried conditions decreased from 56.3 MPa to 51.3 MPa when the CBA content increased from $0 \%$ to $100 \%$. Moreover, a decrease in the compressive strength with increasing CBA content was also observed in the F4 series specimens. Specifically, the compressive strengths of the F4 series specimens under SSD conditions were $3.4 \sim 5.9 \%$ greater than those under oven-dried conditions.

The compressive strength of the concrete at a curing age of 28 days under SSD conditions in this study decreased by $4.2 \sim 15.1 \%$ as the CBA content increased. Meanwhile, the other study [31] showed that the compressive strength of CBA concrete at a curing age of 28 days under SSD conditions decreased by $18.2 \sim 27.3 \%$ as the fine aggregate was replaced with CBA aggregate of $25 \sim 100 \%$ by volume. Therefore, the decrease in compressive strength in this study was less than the decrease in the compressive strength in the previous study. This result could be due to the combined effect of the CBA and fly ash that made the concrete microstructure denser, as discussed by Majhi and Nayak [32], compared to when either CBA or fly ash was used in the concrete mixture.

A comparison of the compressive strengths of the F2 series concrete specimens with different curing ages is shown in Figure 6(b). The compressive strength of CBA concrete with a curing age of 91 days was greater than that with a curing age of 28 days. The improvement in compressive strength with the extended curing age was due to the pozzolanic reaction by the $\mathrm{CBA}$ and fly ash. The pozzolanic reaction of CBA and fly ash developed further with increasing curing time. The comparisons also showed that the effect of curing age on the compressive strength under oven-dried conditions was greater than the effect of curing age on the compressive strength under SSD conditions. This result implied that the development of the pozzolanic reaction with increasing curing age was affected by the curing conditions.
4.4. Ultrasonic Velocity of CBA Concrete. Figure 7(a) shows the comparison of the ultrasonic velocity of CBA concrete under the SSD and oven-dried conditions with a curing age of 28 days. Regarding the F2 series specimens, the ultrasonic velocity of the specimens under oven-dried conditions was $5.8 \sim 6.2 \%$ lower than that of the specimens under SSD conditions. Moreover, regarding the F4 series specimens, the ultrasonic velocity of the specimens under oven-dried conditions was $5.7 \sim 6.6 \%$ lower than that of the specimens under SSD conditions. Therefore, the test results showed that the ultrasonic velocity of CBA concrete was affected by the drying conditions.

The effect of CBA content on the ultrasonic velocity of CBA concrete under the two different drying conditions can be found in Figure 7(a). Regarding the F2 series specimens, the ultrasonic velocity under SSD conditions decreased by $0.9 \sim 3.3 \%$ and the ultrasonic velocity under oven-dried conditions decreased by $3.4 \%$ as the CBA content increased from 0 to $100 \%$.

Figure 7(a) also shows the comparison of the ultrasonic velocity of CBA concrete with different fly ash contents. The specimens containing a high fly ash content showed a low ultrasonic velocity. As an example, the ultrasonic velocities of the F4-BA050 and F4-BA100 specimens were $0.8 \%$ and $1.1 \%$ lower than those of the F2BA050 and F2-BA100 specimens, respectively, under SSD conditions. The ultrasonic velocities of the F4-BA050 and F4-BA100 specimens were $4,033 \mathrm{~m} / \mathrm{s}$ and $3,965 \mathrm{~m} / \mathrm{s}$, while those of the F2-BA050 and F2-BA100 specimens were $4,066 \mathrm{~m} / \mathrm{s}$ and $3,992 \mathrm{~m} / \mathrm{s}$, respectively, under oven-dried conditions. Therefore, the test results indicated that the fly ash content had a slight effect on the ultrasonic velocity of CBA concrete under both the SSD and oven-dried conditions.

Figure 7(b) shows that the ultrasonic velocity of the CBA concrete increased with increasing curing age under both the SSD and oven-dried conditions. Specifically, regarding the concrete specimens containing 25\%, 50\%, 75\%, and $100 \%$ CBA under SSD conditions, the ultrasonic velocity increased by $2.6 \%, 2.7 \%, 3.3 \%$, and $2.4 \%$, respectively, as the curing age was extended from 28 to 91 days.

\section{Relationships between the Thermal Conductivity and Material Properties}

The relationship between the thermal conductivity and the unit weight of CBA concrete under both the SSD and ovendried conditions is shown in Figure 8. The figure shows that the thermal conductivity of CBA concrete had a close relationship with the unit weight.

The replacement of natural aggregate with CBA increased the porosity of the concrete, and concrete with high porosity has a low thermal conductivity. Therefore, the thermal conductivity of CBA concrete decreased due to its high porosity.

Based on the regression analysis, the relation between the thermal conductivity and unit weight was expressed by the following equation: 


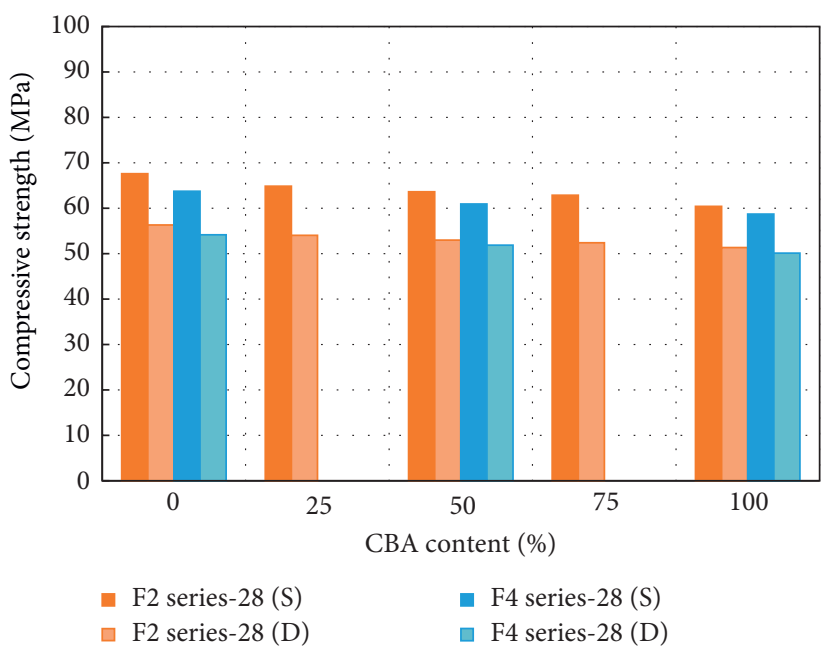

(a)

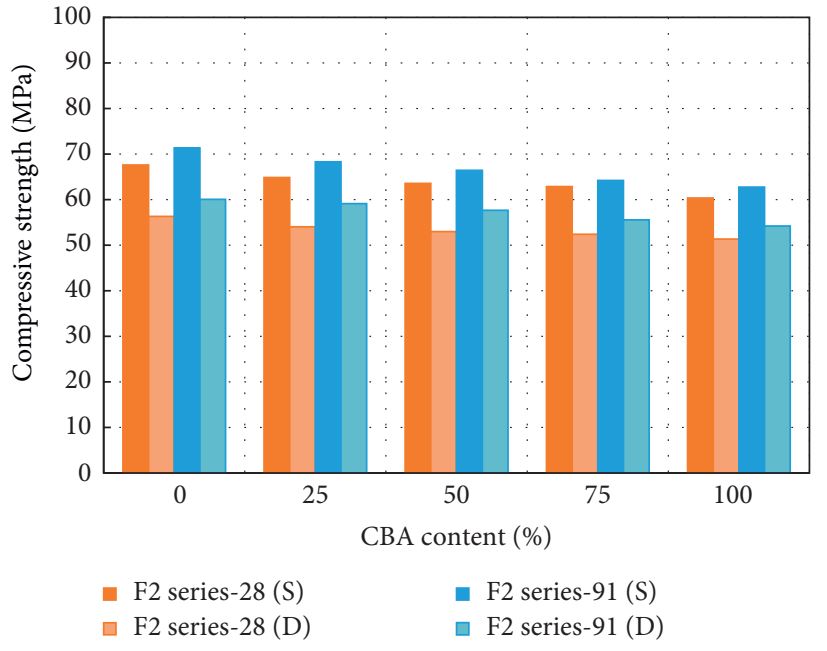

(b)

Figure 6: Compressive strength of CBA concrete. (a) Comparison under different drying conditions. (b) Comparison at different curing ages.

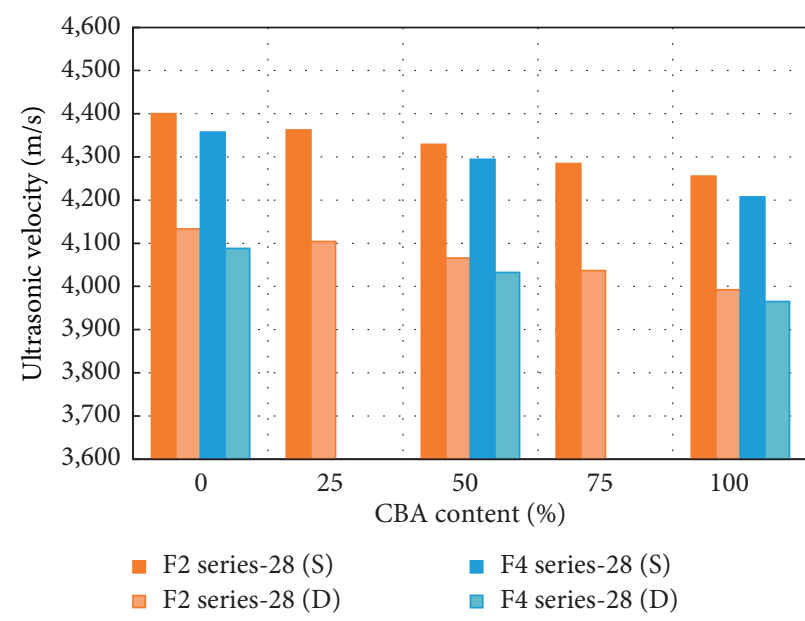

(a)

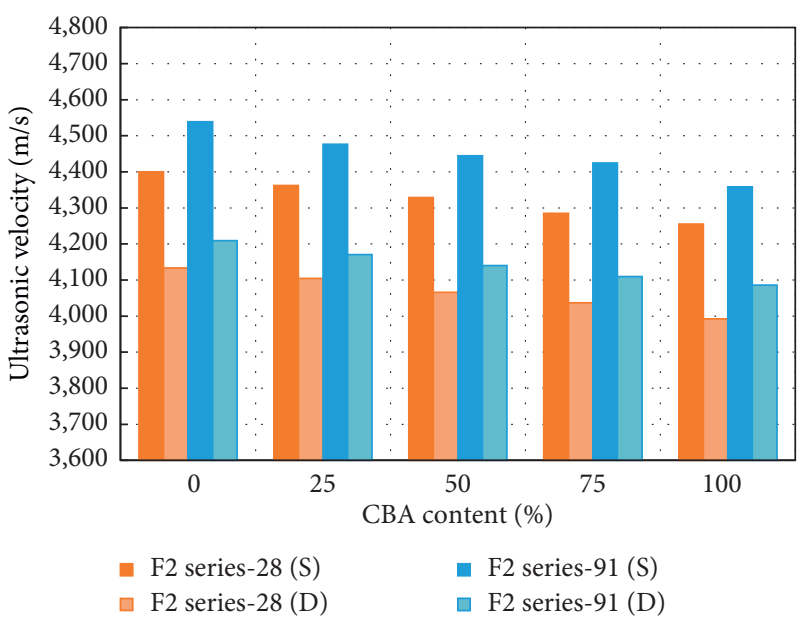

(b)

Figure 7: Ultrasonic velocity of CBA concrete. (a) Comparison under different drying conditions. (b) Comparison at different curing ages.

$$
\begin{aligned}
k & =0.0155 e^{0.0021 \nu}, \\
R^{2} & =0.9273,
\end{aligned}
$$

where $k$ is the thermal conductivity $(\mathrm{W} / \mathrm{mK})$ and $v$ is the unit weight $\left(\mathrm{kg} / \mathrm{m}^{3}\right)$. The coefficient of determination $\left(R^{2}\right)$ of this equation was close to 1 , which implied that the equation could be used to precisely predict the thermal conductivity.

The relationship between the thermal conductivity and compressive strength of CBA concrete under both the SSD and oven-dried conditions is also shown in Figure 9. The thermal conductivity of CBA concrete increased linearly with the compressive strength. An exponential equation for predicting the thermal conductivity of CBA concrete by using the compressive strength is suggested as follows:

$$
\begin{aligned}
k & =0.4626 e^{0.0205 f_{c},} \\
R^{2} & =0.9325,
\end{aligned}
$$

where $k$ is the thermal conductivity $(\mathrm{W} / \mathrm{m} \bullet \mathrm{K})$ and $f_{c}$ is the compressive strength $(\mathrm{MPa})$. This equation could be used to accurately predict the thermal conductivity because the coefficient of determination of this equation was close to 1 .

Finally, the relationship between the thermal conductivity and ultrasonic velocity is shown in Figure 10. The relationship between the thermal conductivity and ultrasonic velocity of CBA concrete was close, as was the relationship between the thermal conductivity and unit weight and compressive strength of CBA concrete. The prediction for the thermal conductivity by measuring the ultrasonic velocity was suggested as follows: 


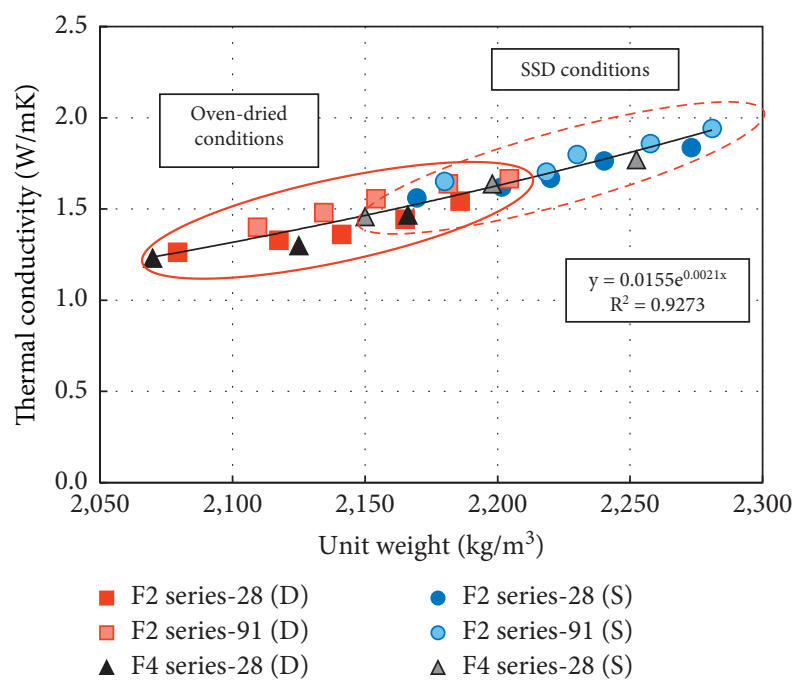

FIGURE 8: Relationship between the thermal conductivity and unit weight.

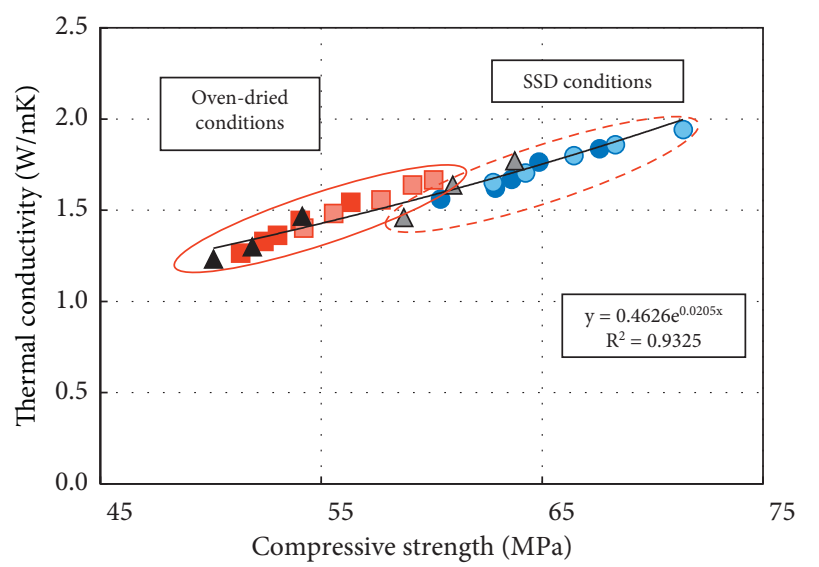
- F2 series-28 (D)
- F2 series-28 ( $\mathrm{S}$ )
ㄷ2 series-91 (D)
- F2 series-91 (S)
A F4 series-28 (D)
$\triangle$ F4 series-28 (S)

FIGURE 9: Relationship between the thermal conductivity and compressive strength.

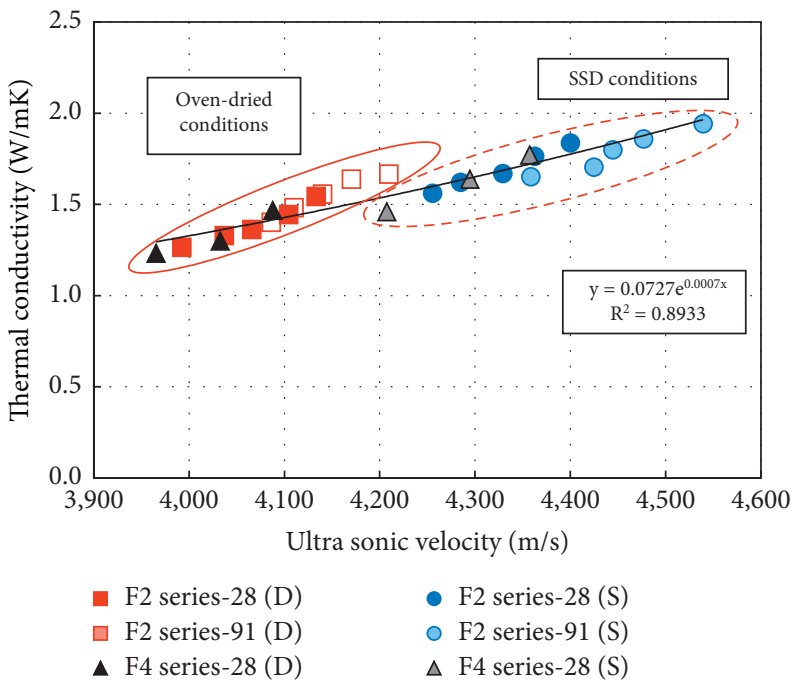

FIGURE 10: Relationship between the thermal conductivity and ultrasonic velocity. 


$$
\begin{aligned}
k & =0.0727 e^{0.0007 V}, \\
R^{2} & =0.8933,
\end{aligned}
$$

where $k$ is the thermal conductivity $(\mathrm{W} / \mathrm{m} \bullet \mathrm{K})$ and $V$ is the ultrasonic velocity $(\mathrm{m} / \mathrm{s})$. The proposed equation predicted the thermal conductivity well because the coefficient of determination $R^{2}$ of this equation was close to 1 .

\section{Conclusions}

This research was carried out to evaluate the effects of the curing and drying conditions on the thermal conductivity and material properties of CBA concrete. In addition, the effects of the CBA and fly ash levels on the thermal conductivity of CBA concrete were investigated. Based on the extensive test results, the conclusions of this study can be drawn as follows:

(1) The test results revealed that curing and drying conditions had an effect on the unit weight of CBA concrete. Compared with that under SSD conditions, the unit weight of CBA concrete under the ovendried conditions decreased by approximately 3 4\%. This decrease in unit weight might be due to water evaporation from the CBA aggregate and hydration degree of concrete under different curing conditions.

(2) The drying conditions considerably affected the thermal conductivity of CBA concrete. The thermal conductivity of CBA concrete decreased significantly when the specimens had low moisture contents. The thermal conductivity of CBA concrete decreased by $15 \sim 20 \%$ under the oven-dried conditions. In addition, the thermal conductivity of CBA concrete also decreased significantly with increasing CBA content. Moreover, the influence of the fly ash content on the thermal conductivity of CBA concrete was not significant.

(3) The curing and drying conditions influenced the compressive strength of CBA concrete. The compressive strength of CBA concrete decreased by $14 \sim 16 \%$ under the oven-dried conditions. Additionally, the replacement of fine aggregate with CBA decreased the compressive strength of the resulting concrete.

(4) The ultrasonic velocity in CBA concrete was considerably affected by the drying conditions. Specifically, the ultrasonic velocity was approximately $6 \%$ lower when the drying conditions were changed from SSD conditions to oven-dried conditions. In addition, the ultrasonic velocity in CBA concrete decreased by approximately $3.3 \%$ when CBA level was increased.

(5) The relationships between the thermal conductivity and unit weight, compressive strength, and ultrasonic velocity were proposed, which included the test results under both the SSD and oven-dried conditions. These relationships could be applied to predict the thermal conductivity of $\mathrm{CBA}$ concrete by measuring the three material properties mentioned above.

\section{Data Availability}

The data used to support the findings in this study are available from the corresponding author upon request.

\section{Conflicts of Interest}

The authors declare that they have no conflicts of interest regarding the publication of this manuscript.

\section{Acknowledgments}

This research was supported by the Ministry of Trade, Industry and Energy (MOTIE) and the Korea Institute of Energy Research (KETEP) (no. 20181110200070).

\section{References}

[1] F. Koksal, O. Gencel, and M. Kaya, "Combined effect of silica fume and expanded vermiculite on properties of lightweight mortars at ambient and elevated temperatures," Construction and Building Materials, vol. 88, pp. 175-187, 2015.

[2] C. Tasdemir, O. Sengul, and M. A. Tasdemir, "A comparative study on the thermal conductivities and mechanical properties of lightweight concretes," Energy and Buildings, vol. 151, pp. 469-475, 2017.

[3] I. Asadi, P. Shafigh, Z. F. B. Abu Hassan, and N. B. Mahyuddin, "Thermal conductivity of concrete-a review," Journal of Building Engineering, vol. 20, pp. 81-93, 2018.

[4] A. L. Brooks, H. Zhou, and D. Hanna, "Comparative study of the mechanical and thermal properties of lightweight cementitious composites," Construction and Building Materials, vol. 159, pp. 316-328, 2018.

[5] I. H. Yang and J. Park, "A study on the thermal properties of high-strength concrete containing CBA fine aggregates," Materials, vol. 13, no. 7, 2020.

[6] M. Singh, "1-coal bottom ash," in Woodhead Publishing Series In Civil And Structural Engineering, R. Siddique and P. B. T.W. and S. C. M. in C. Cachim, Ed., Woodhead Publishing, Sawston, UK, pp. 3-50, 2018.

[7] E. Baite, A. Messan, K. Hannawi, F. Tsobnang, and W. Prince, "Physical and transfer properties of mortar containing coal bottom ash aggregates from Tefereyre (Niger)," Construction and Building Materials, vol. 125, pp. 919-926, 2016.

[8] C. Ngohpok, V. Sata, T. Satiennam, P. Klungboonkrong, and P. Chindaprasirt, "Mechanical properties, thermal conductivity, and sound absorption of pervious concrete containing recycled concrete and bottom ash aggregates," KSCE Journal of Civil Engineering, vol. 22, no. 4, pp. 1369-1376, 2018.

[9] J.-H. Park, Q.-T. Bui, S.-H. Jung, and I.-H. Yang, "Selected strength properties of coal bottom ash (CBA) concrete containing fly ash under different curing and drying conditions," Materials, vol. 14, no. 18, p. 5381, 2021.

[10] S. Gooi, A. A. Mousa, and D. Kong, "A critical review and gap analysis on the use of coal bottom ash as a substitute constituent in concrete," Journal of Cleaner Production, vol. 268, Article ID 121752, 2020.

[11] RILEM, Fly Ash in Concrete: Properties and Performance, RILEM, London, UK, 1991. 
[12] H. Zhou and A. L. Brooks, "Thermal and mechanical properties of structural lightweight concrete containing lightweight aggregates and fly-ash cenospheres," Construction and Building Materials, vol. 198, pp. 512-526, 2019.

[13] A. Ghosh, A. Ghosh, and S. Neogi, "Reuse of fly ash and bottom ash in mortars with improved thermal conductivity performance for buildings," Heliyon, vol. 4, no. 11, Article ID e00934, 2018.

[14] M. I. Khan, "Factors affecting the thermal properties of concrete and applicability of its prediction models," Building and Environment, vol. 37, no. 6, pp. 607-614, 2002.

[15] W. Zhang, H. Min, X. Gu, Y. Xi, and Y. Xing, "Mesoscale model for thermal conductivity of concrete," Construction and Building Materials, vol. 98, pp. 8-16, 2015.

[16] American Concrete Institute, "Standard Practice for Selecting Proportions for Normal Heavyweight, and Mass Concrete (ACI 211.1-91) Reapproved 1997," Reported by ACI Committee 211, American Concrete Institute, Michigan, MI, USA, 1997.

[17] Korea Industrial Standard, Standard Test Method for Compressive Strength of concrete; Ks F. 2405, Korea Industrial Standards, Seoul, Republic of Korea, 2010.

[18] ASTM, Standard Practice for Making and Curing Concrete Test Specimens in the Laboratory; ASTM C192/C192M-02, ASTM, West Conshohocken, PA, USA, 2002.

[19] ASTM, Standard Test Method for Determination of Thermal Conductivity of Soil and Soft Rock by Thermal Needle Probe Procedure; ASTM D5334-05, ASTM, West Conshohocken, PA, USA, 2005.

[20] K.-H. Kim, S.-E. Jeon, J.-K. Kim, and S. Yang, "An experimental study on thermal conductivity of concrete," Cement and Concrete Research, vol. 33, no. 3, pp. 363-371, 2003.

[21] S. E. Gustafsson, "Transient plane source techniques for thermal conductivity and thermal diffusivity measurements of solid materials," Review of Scientific Instruments, vol. 62, no. 3 , pp. 797-804, 1991.

[22] T. Log and S. E. Gustafsson, "Transient plane source (TPS) technique for measuring thermal transport properties of building materials," Fire and Materials, vol. 19, no. 1, pp. 43-49, 1995.

[23] ASTM, Standard Test Method for Pulse Velocity through Concrete; ASTM C597-02, ASTM, West Conshohocken, PA, USA, 2002.

[24] A. Ashrafian, M. J. Taheri Amiri, M. Rezaie-Balf, T. Ozbakkaloglu, and O. Lotfi-Omran, "Prediction of compressive strength and ultrasonic pulse velocity of fiber reinforced concrete incorporating nano silica using heuristic regression methods," Construction and Building Materials, vol. 190, pp. 479-494, 2018.

[25] A. S. Nikand and O. L. Omran, "Estimation of compressive strength of self-compacted concrete with fibers consisting nano-SiO2 using ultrasonic pulse velocity," Construction and Building Materials, vol. 44, pp. 654-662, 2013.

[26] Y. Liu, C. Ma, D. Wang, Y. Wang, and J. Liu, "Nonlinear effect of moisture content on effective thermal conductivity of building materials with different pore size distributions," International Journal of Thermophysics, vol. 37, no. 6, p. 56, 2016.

[27] D. J. Gawin, J. Kosny, and K. Wilkes, "Thermal conductivity of moist cellular concrete-experimental and numerical study," in Proceedings of Performance of Exterior Envelopes of Whole Buildings IX, American Society of Heating, Refrigerating and Air-Conditioning Engineers-ASHRAE, Tallahassee, FL, USA, December 2004.
[28] L. H. Nguyen, A.-L. Beaucour, S. Ortola, and A. Noumowé, "Experimental study on the thermal properties of lightweight aggregate concretes at different moisture contents and ambient temperatures," Construction and Building Materials, vol. 151, pp. 720-731, 2017.

[29] N. F. Basirun, M. H. W. Ibrahim, N. J. Jamaludin, and R. P. Jaya, "A review: the effect of grinded coal bottom ash on concrete," In MATEC Web of Conferences ISCEE, vol. 103, Article ID 01007, 2017.

[30] M. Singh and R. Siddique, "Effect of coal bottom ash as partial replacement of sand on workability and strength properties of concrete," Journal of Cleaner Production, vol. 112, pp. 620630, 2016.

[31] M. Rafieizonooz, J. Mirza, M. R. Salim, M. W. Hussin, and E. Khankhaje, "Investigation of coal bottom ash and fly ash in concrete as replacement for sand and cement," Construction and Building Materials, vol. 116, pp. 15-24, 2016.

[32] R. K. Majhi and A. N. Nayak, "Properties of concrete incorporating coal fly ash and coal bottom ash," Journal of the Institution of Engineers, vol. 100, no. 3, pp. 459-469, 2019. 